\title{
Mixed Nectar of Cupuassu (Theobroma grandiflorum) and Green Tea and the Effect of Preservatives and Storage on Nutritional and Sensorial Characteristics
}

\author{
Gabrielli Nunes CLÍMACO ${ }^{1}$, Virgínia Kelly Gonçalves ABREU ${ }^{2}$, Tatiana De Oliveira LEMOS ${ }^{2}$, \\ Ana Lúcia Fernandes PEREIRA, \\ ${ }^{1}$ Programa de Pós-Graduação em Engenharia de Alimentos, Universidade Estadual de Maringá, Campus Maringá, \\ Avenida Colombo, 5790, Jd. Universitário, CEP 87020-900, Maringá, Paraná \\ ${ }^{2}$ Curso de Engenharia de Alimentos, Universidade Federal do Maranhão, Centro de Ciências Sociais, \\ Saúde e Tecnologia, Campus Avançado, Avenida da Universidade, s/n, CEP 65914-535, Imperatriz, Maranhão \\ *Corresponding author: anafernandesp@gmail.com
}

Received January 10, 2019; Revised March 25, 2019; Accepted April 27, 2019

\begin{abstract}
The production of mixed nectar of cupuassu and green tea nectar can be a promising product for the market of beverage because it can provide a product with high nutritional value and good acceptance. The study aimed to produce mixed nectar of cupuassu and green tea with high nutritional value and good sensory acceptance and evaluate its stability. Physico-chemical ( $\mathrm{pH}$, acidy, reducing and total sugars, phenolic compounds, antioxidant activity, phase separation, and color), microbiological and sensory analysis were performed. Firstly, it was determined the ideal ratio of vegetables using formulations containing cupuassu and green tea, respectively: F1 (30\%/ 70\%), F2 (50\%/ 50\%) and F3 (70\%/ 30\%). Higher antioxidant activity and sensory acceptance selected F2. After, it was determined the ideal concentration of sugars. For this, it was produced formulations with 11, 13 and $15{ }^{\circ}$ Brix. According to sensory acceptance, was chosen the formulation with $13^{\circ}$ Brix. After, it was assessed the stability for 180 days, with and without preservatives. The samples without preservatives had changes in the sensory characteristics during storage. However, these characteristics were maintained in the acceptance region of the hedonic scale.
\end{abstract}

Keywords: blends, exotic fruits, phenolics compounds, hedonic scale, antioxidant activity, additives

Cite This Article: Gabrielli Nunes CLÍMACO, Virgínia Kelly Gonçalves ABREU, Tatiana De Oliveira LEMOS, and Ana Lúcia Fernandes PEREIRA, "Mixed Nectar of Cupuassu (Theobroma grandiflorum) and Green Tea and the Effect of Preservatives and Storage on Nutritional and Sensorial Characteristics.” Journal of Food and Nutrition Research, vol. 7, no. 5 (2019): 361-369. doi: 10.12691/jfnr-7-5-5.

\section{Introduction}

The fruit juices play essential roles in human health, being a crucial part of nutrition. Its consumption is associated with the reduced mortality risk since that contain high amounts of nutrients essential, phytochemicals, fibers and other bioactive compounds that promote health benefits [1,2].

Mixed fruit juices and nectars are more popular than pure juices because they enable the combining of bioactive compounds and flavors [3]. Reference [4] produced a mixed beverage of snake tomato and pineapple. These authors reported that was possible to obtain the bioactive compounds such as carotenoids, flavonoids, and phenolic acids from snake tomato and the good acceptance because the pineapple to have reduced the astringent flavor of snake tomato. Reference [5] evaluated the effects of blends of pineapple, orange, carrot, and Hibiscus sabdariffa extracts (HSE) to obtain a combination with optimal antioxidant properties and good sensory acceptance. These authors reported than beverage containing $40.00 \%$ of pineapple, $16.46 \%$ of carrot, $17.20 \%$ of orange and $26.30 \%$ of HSE provided the production of functional drinks. Thus, the blends improve the nutritional properties and sensory acceptance of the beverages.

In this context, green tea is one of the most popular beverages consumed worldwide which is obtained from the leaves of Camellia Sinensis, originating in China. As a result of scientific evidence on its beneficial effects for health, the consumers have sought to increase its consume. It has been reported that daily consumption of green tea decreases blood pressure, reduces the risk of coronary diseases and obesity. Moreover, it has been said to have antimicrobial activity [6,7].

These effects are associated with the green tea composition that contains several polyphenolic components with antioxidant properties. The predominant active elements are the flavanol monomers known as catechins (25-35\%), where epigallocatechin-3-gallate and epicatechin-3-gallate are the most effective antioxidant compounds. Despite the 
high nutritional value of the green tea, its characteristic taste includes a mixture of bitterness, astringency, meaty flavor, sweetness and slight sourness. Thus, it was not well accepted by many consumers $[8,9]$.

Therefore, to improve the sensory acceptance of green tea, reference [10] produced a mixed juice of green tea and pineapple. These authors concluded that formulation with a ratio of 60/40 (pineapple/ green tea) was well accepted by consumers, having more than $70 \%$ of the acceptability index.

Cupuassu (Theobroma grandiflorum) is a tropical fruit native to the Brazilian Amazon. Its pulp is yellowish-white and is used for the production of ice cream, juice, and jellies because of its distinctive flavor, being good sensory acceptance $[11,12,13]$. Moreover, the cupuassu pulp has high nutritional value due to the phenolic compounds $[14,15]$. The cupuassu pulp is rich in fibers and contains a considerable amount of starch as well as pectin polysaccharides [16], which can provide a different texture when compared with other fruit pulps. In this context, the mixed nectar production containing cupuassu and green tea can offer high nutritional value and good sensory acceptance.

The shelf-life of the fruit beverages is influenced by product characteristics, environment, and storage [17]. Food preservatives are added to products to ensure microbiological safety and to preserve sensory characteristics 18]. However, in recent years some beverage has been commercialized without the preservatives addition after the pasteurization process. This is due to researchers have studied their potential adverse effects on health and consumer safety. Although most food preservatives are safe, their use should be restricted to achieve a technological benefit, and in some cases, the amounts of food preservatives are strictly controlled by food regulations [19]. In the literature, no contains references on the effect of preservatives addition in cupuassu nectar during storage.

Therefore, this study aimed to produce mixed nectar of cupuassu and green tea. Moreover, was evaluated the influence of food preservatives and the storage on the quality characteristics and sensory acceptance of the product.

\section{Material and Methods}

In the present study were used commercial cupuassu pulps and green tea infusion. The green tea infusion was prepared by immersion of herb for 3 minutes in water at $100^{\circ} \mathrm{C}$. The study was divided into three stages. First, the ideal ratio of cupuassu and green tea in the mixed base of the nectar was determined. The nectars were produced with $30 \%$ of the mixed base. The soluble solids were standardized by addition of sucrose up to $11^{\circ}$ Brix. Three formulations were produced with cupuassu pulp and green tea ratios, respectively: 30/70 (F1), 50/50 (F2) and 70/30 (F3). After, the ideal sweetness in the mixed nectar was determined. For this, three formulations with total soluble solids of 11,13 and $15^{\circ}$ Brix were produced from the best ratio of vegetables obtained initially. Finally, the effect of food preservatives (40 ppm of sodium metabisulfite and $500 \mathrm{ppm}$ of potassium sorbate) and storage for 180 days was evaluated. Thus, the nectars were analyzed following the treatments: day 0 without preservatives (T1), day 0 with preservatives (T2), day 180 without preservatives (T3), and day 180 with preservatives (T4).

\subsection{Experimental Design}

For the ideal ratio of cupuassu and green tea was followed a complete randomized factorial $3 \times 5$ design ( 3 formulations and 5 replicates). The ideal sugar determination also followed a complete randomized factorial 3x5 design ( 3 treatments and 5replicates). For the storage time, the experiment followed a full randomized factorial (2 treatments and 2 storage times), with 5 replicates per treatment on each storage time.

\subsection{Production of the Mixed Nectar of Cupuassu and Green Tea}

The nectars blends were pasteurized using hot-fill processing at $90{ }^{\circ} \mathrm{C}$ for $60 \mathrm{~s}$ and cooled water. For the storage, the samples of the $\mathrm{T} 2$ and $\mathrm{T} 4$ were added of 40 ppm of sodium metabisulfite and 500 ppm of potassium sorbate before pasteurization.

After processing, the samples of the first stage was analyzed for $\mathrm{pH}$, titratable acidity, reducing and total sugars, phenolic compounds, antioxidant activity, and sedimentation index and sensorial evaluation. Samples from the second experiment were submitted only the sensory evaluation. The nectars produced for the storage time were maintained at room temperature $\left(25^{\circ} \mathrm{C}\right)$ and analyzed for microbiological determinations (coliforms at $35^{\circ} \mathrm{C}$, molds, and yeasts), $\mathrm{pH}$, titratable acidity, reducing and total sugars, phenolic compounds, antioxidant activity, color, and sensorial evaluation.

\section{3. pH and Titratable Acidity Analysis}

The $\mathrm{pH}$ was determined by the direct measurement in a Potentiometer (Biotech, mPA-210, Piracicaba, Brasil). The titratable acidity (TA) was measured by titrating with $0.10 \mathrm{M} \mathrm{NaOH}$. The results were expressed in gram (g) of citric acid / $100 \mathrm{~mL}$ [20].

\subsection{Reducing and Total Sugars and Soluble Solids Analysis}

The content of reducing sugars was determined spectrophotometrically using 3.5-dinitrosalicylic acid (DNS). For the total sugars, an acidic inversion was carried out, and then the total sugars were determined using the DNS [21]. The results were expressed in gram (g) glucose/ $100 \mathrm{~mL}$. The soluble solids determination was performed directly using the digital refractometer (HI96801, Hanna, Woonsocket, USA).

\subsection{Total Phenolic Content and Antioxidant Activity Determination}

The total phenolic content was evaluated according to Reference [22]. This method determined the ability of phenolic compounds to reduce the mixture of phosphomolybdic/phosphotungstic acid complexes in 
alkaline medium. After $30 \mathrm{~min}$ of reaction, the reading was taken at $765 \mathrm{~nm}$ using spectrophotometer (Biospectro, SP-220, Curitiba, Brasil). Gallic acid was the reference standard.

ABTS and DPPH methods were used for the antioxidant activity evaluation. For the ABTS method, the radical was produced by reacting of the ABTS stock solution (7 mM) with potassium persulfate $(140 \mathrm{mM})$. The $\mathrm{ABTS}^{-+}$radical was diluted with ethanol to an absorbance of 0.700 at 734 $\mathrm{nm}$. Aliquots of $30 \mu \mathrm{L}$ of the nectars extracts were mixed to $3000 \mu \mathrm{L}$ of $\mathrm{ABTS}^{-+}$radical, and the absorbance was measured after 6 min. Results were expressed as Trolox equivalent antioxidant activity/mL [23].

The DPPH method was performed according to Reference [24] with modifications. The $\mathrm{DPPH}^{+}$radical was prepared with methanol $(0.119 \mathrm{mM} / \mathrm{L})$. Aliquots of $30 \mu \mathrm{L}$ of the nectars extracts were mixed to $2 \mathrm{~mL}$ of $\mathrm{DPPH}^{+}$radical, and the absorbance was measured after $30 \mathrm{~min}$. Results were expressed as Trolox equivalent antioxidant activity/ mL.

\subsection{Sedimentation Index Determination}

The mixed nectars were transferred to graduated $50 \mathrm{~mL}$ tubes, stored at $25^{\circ} \mathrm{C}$ and measured for 10 days. The sedimentation height was measured on a millimeter scale at regular intervals of $24 \mathrm{~h}$. The sedimentation index (\%SI) was calculated using the equation: $\mathrm{SI}=(\mathrm{Ht} / \mathrm{Ho})$. 100; where: Ht is the height of the sedimented phase after time $\mathrm{t}$ and Ho is first height $[25,26]$.

\subsection{Instrumental Color Analysis}

The nectar's color was determined by a Minolta spectrophotometer (Minolta, CM 2300D, Tokyo, Japão), operating in the system CIE ( $\mathrm{L}^{*}, \mathrm{a}^{*}$, and $\left.\mathrm{b}^{*}\right)$, with the apparatus calibration performed by the white ceramic plate, using the D65 illuminant.

\subsection{Microbiological Analyses}

Coliforms at $35^{\circ} \mathrm{C}$, molds and yeasts determinations were performed following the methodology of Reference [27].

\subsection{Sensory Acceptance}

Sensory evaluation was performed by 60 untrained panelists of both sexes, who were selected by like and consumed cupuassu. Samples $(40 \mathrm{~mL})$ were served individually in a monadic sequential order using a balanced block design in standard sensory booths. Nectars were served at the $7^{\circ} \mathrm{C}$ in glass cups. The acceptance tests were conducted for the evaluation of color, appearance, aroma, flavor, sweetness, acidity, body, and overall acceptance. The hedonic scale was used, ranging from 1 (dislike extremely) to 9 (like extremely) [28].

\subsection{Statistical Analysis}

One-way ANOVA analyzed the parameters $\mathrm{pH}$, TA, reducing and total sugars, phenolic compounds, antioxidant activity, sedimentation index, and instrumental color with post hoc Tukey test at the 95\% confidence level $(\mathrm{p}<0.05)$.

For sensory data, treatments were considered as a fixed source of variation and the consumer as a random effect. The non-parametric Friedman test analyzed the attributes color, appearance, aroma, flavor, sweetness, acidity, body, and overall acceptance at the 95\% confidence level $(\mathrm{p}<0.05)$. Moreover, the Principal component analysis (PCA) was performed to visualize how the treatments were affected (in the three stages) on the overall acceptance attribute. All statistical analyses were performed using XLSTAT software (Addinsoft, Paris, France).

\section{Results and Discussion}

\subsection{The Ratio of Cupuassu and Green Tea in the Mixed Nectar}

The $\mathrm{pH}$ did not change significantly ( $\mathrm{p}>0.05)$ among treatments (Table 1). This $\mathrm{pH}$ is essential for the nectars because values higher than 4.5 favors the Clostridium botulinum growth [2]. Herein, all the samples studied had $\mathrm{pH}$ below of this value. The low $\mathrm{pH}$ obtained for nectars was provided by cupuassu pulp (Table 1). Therefore, the pulp contributed positively to the final $\mathrm{pH}$.

For the titratable acidity, F3 had the highest values, followed by F1. This result is resultant to the higher cupuassu pulp content in the formulation. The cupuassu has higher TA than green tea (Table 1). Similar results were reported by Reference [10] in the blend juices of pineapple and green tea.

Table 1. Mean values and standard deviation of the physicochemical analyzes of cupuassu pulp, green tea infusion and mixed nectar of cupuassu and green tea with different ratio of vegetables in the mixed base

\begin{tabular}{|c|c|c|c|c|c|}
\hline \multirow[b]{2}{*}{ Parameters } & \multirow{2}{*}{ Cupuassu pulp } & \multirow{2}{*}{ Green tea } & \multicolumn{3}{|c|}{ Formulations $^{1}$} \\
\hline & & & F1 & $\mathrm{F} 2$ & F3 \\
\hline $\mathrm{pH}$ & $2.97 \pm 0.00$ & $5.64 \pm 0.00$ & $3.32 \pm 0.05 a$ & $3.25 \pm 0.05^{\mathrm{a}}$ & $3.25 \pm 0.03 a$ \\
\hline Titratable acidity $^{2}$ & $2.00 \pm 0.00$ & $0.04 \pm 0.00$ & $0.21 \pm 0.02 \mathrm{c}$ & $0.34 \pm 0.02 b$ & $0.46 \pm 0.02 \mathrm{a}$ \\
\hline Reducing sugars ${ }^{3}$ & $3.33 \pm 0.00$ & $0.00 \pm 0.00$ & $2.88 \pm 0.98 a$ & $3.20 \pm 0.89^{a}$ & $3.52 \pm 0.29 a$ \\
\hline Total sugars ${ }^{3}$ & $9.77 \pm 0.51$ & $2.67 \pm 0.16$ & $10.89 \pm 1.26 a$ & $10.46 \pm 0.49^{\mathrm{a}}$ & $11.06 \pm 3.16 \mathrm{a}$ \\
\hline Phenolic compounds ${ }^{4}$ & $117.14 \pm 8.21$ & $232.47 \pm 2.10$ & $99.21 \pm 6.44 \mathrm{a}$ & $90.15 \pm 15.30^{\mathrm{a}}$ & $79.88 \pm 11.65 a$ \\
\hline $\mathrm{AA}(\mathrm{ABTS})^{5}$ & $0.45 \pm 0.04$ & $0.70 \pm 0.01$ & $0.47 \pm 0.05 a$ & $0.46 \pm 0.03^{\mathrm{a}}$ & $0.42 \pm 0.02 \mathrm{a}$ \\
\hline $\mathrm{AA}(\mathrm{DPPH})^{5}$ & $0.05 \pm 0.03$ & $0.18 \pm 0.03$ & $0.14 \pm 0.02 \mathrm{a}$ & $0.14 \pm 0.01^{\mathrm{a}}$ & $0.09 \pm 0.02 b$ \\
\hline Sedimentation index ${ }^{6}$ & - & - & $71.22 \pm 7.49 b$ & $80.58 \pm 7.68 \mathrm{ab}$ & $87.96 \pm 3.06 a$ \\
\hline
\end{tabular}

Means with different letters in the formulation's columns differ according to the Tukey test (p<0.05). ${ }^{1} \mathrm{~F} 1: 30 \%$ cupuassu pulp / $70 \%$ green tea; F2: $50 \%$ cupuassu pulp / 50\% green tea; F3: 70\% cupuassu pulp / 30\% green tea. ${ }^{2} \mathrm{~g} / 100 \mathrm{~mL}$ of citric acid; ${ }^{3} \mathrm{~g} / 100 \mathrm{~mL}$ of glucose; ${ }^{4} \mathrm{mg}$ of galic acid/ $100 \mathrm{~mL}$; 5AA = antioxidant activity $(\mu \mathrm{M}$ Trolox $/ \mathrm{mL}) ;{ }^{6} \%$. 
The reducing and total sugars did not change $(\mathrm{p}>0.05)$ among treatments. In the present study, the reducing sugars in nectars were provided by cupuassu pulp $(3 \mathrm{~g} / 100 \mathrm{~mL})$ because the green tea did not have these compounds (Table 1). The reference [29], producing blends of vegetable Hibiscus sabdariffa with tropical fruits also reported that the fruits provided the reducing sugars for the beverages. For total sugars, the similarity of values among treatments was expected because the soluble solids were standardized up to $11^{\circ}$ Brix in the nectar production. Thus, since these sugars are most likely the major contributors to soluble solids, these components are usually correlated to total sugars [30].

The phenolic compounds content did not change ( $>0.05$ ) between the formulations. The Reference [31] reported that epigallocatechin gallate and flavonols are the main phenolic compounds in green tea, which are sensitive to thermal. Therefore, the similar content of the mixed nectar can be of the reduction of these phenolics during pasteurization. The reference [32] evaluated the phenolic contents of fresh exotic fruits, cultivated in the northeastern of Brazil. These authors reported that mangaba, tamarind, and sweetsop had high amounts of phenolics $(81.7 \pm 4.0-98.8 \pm 5.6 \mathrm{mg}$ of $/ 100 \mathrm{~g})$. In the present study, the phenolic compounds values ranged from $79.88 \pm 11.65$ to $99.21 \pm 6.44 \mathrm{mg} / 100 \mathrm{~mL}$. Thus, the mixed nectars can be considered with high nutritional value, for the high phenolic contents.

The antioxidant activity of nectars was measured using ABTS and DPPH free radical methods. The reference [33], evaluating the antioxidant activity in green tea reported that as most natural antioxidants are multifunctional, the antioxidant capacities of samples cannot be described by one single method. For the ABTS, there was no difference between formulations. In contrast, for the DPPH method, F3 had the lowest values $(\mathrm{p}<0.05)$ (Table 1$)$. Therefore, the results indicate that the DPPH method was more sensitive in the determination of the antioxidant activity of mixed nectar because there was a reaction between the $\mathrm{DPPH}$ radical and the antioxidants compounds of the beverage, not observed with ABTS. This result obtained for the DPPH method is a consequence of the antioxidant activity of the raw materials used since the green tea had higher antioxidant activity than the cupuassu pulp (Table 1).

Sedimentation index of F3 was higher $(p<0.05)$ than F1.
$\mathrm{F} 2$, on the other hand, did not differ ( $>>0.05)$ from $\mathrm{F} 1$ and F3 (Table 1). According to reference [34], by Stokes Law, the particle sedimentation velocity is directly proportional to its squared diameter, the acceleration imposed and the difference between the particle and dispersant medium density. Thus, the predominant large particles in cupuassu pulp provided higher sedimentation index in F3. This index in juices is associated with stability mixed base. An increase in this index is perceived negatively by consumers.

All sensory attributes were positively scored, with a rating between "like slightly" and "like very much" (6-8) (Table 2). Therefore, it is possible to infer that all formulations, constitute good market alternatives.

For the color, aroma and body attributes, F3 had higher acceptance when compared with F1. The nectars of F2 did not differ those others formulations. The flavor of F2 had higher $(p<0.05)$ acceptance when compared with F1. The F3 did not change of the other formulations. Sweetness and acidity did not differ ( $\mathrm{p}>0.05)$ among the formulations. For the appearance and overall acceptance, F2 and F3 had high acceptance than F1 (Table 2). In general, these results indicate that the higher ratio of green tea in the nectars reduced the approval of the product.

According to Reference [6], color and appearance are the essential attributes of beverages. These authors reported that the dark color of green tea was associated with low sensory scores. Thus, the little acceptance for color and appearance of F1 is related to this coloration of green tea.

For the aroma, the reference [35] produced blend juice with pomegranate and green tea and evaluated the sensory characteristics. The panelists of the study defined the terms green and green tea-like to the aroma of green tea. These authors reported that samples with higher intensity in these terms were the least liked ones and were perceived to be too low in fruity aroma. Therefore, the high concentration of aromatic compounds of green tea reduced beverage acceptance.

The result for the body can be due to pulp cupuassu characteristics. According to reference [16], the cupuassu pulp has a particular chemical composition, rich in fibers, and contains a considerable amount of starch as well as pectin polysaccharides, which can provide more sticky texture than other fruit pulps. Thus, the high acceptance for F3 can be resultant of high sticky of nectars.

Table 2. Mean values and standard deviation of the sensory attributes color, appearance, aroma, flavor, sweetness, acidity, body and overall acceptance of mixed nectar of cupuassu and green tea with different ratio of vegetables in the mixed base

\begin{tabular}{lccc}
\hline \multirow{2}{*}{ Attributes } & \multicolumn{3}{c}{ Formulations ${ }^{1}$} \\
\cline { 2 - 4 } & F1 & F2 & F3 \\
\hline Color & $6.88 \pm 1.62 \mathrm{~b}$ & $7.28 \pm 1.49 \mathrm{ab}$ & $7.65 \pm 1.25^{\mathrm{a}}$ \\
Appearance & $6.65 \pm 1.67 \mathrm{~b}$ & $7.28 \pm 1.42 \mathrm{a}$ & $7.52 \pm 1.14^{\mathrm{a}}$ \\
Aroma & $6.62 \pm 1.89 \mathrm{~b}$ & $6.88 \pm 1.76 \mathrm{ab}$ & $7.30 \pm 1.39^{\mathrm{a}}$ \\
Flavor & $5.67 \pm 2.03 \mathrm{~b}$ & $6.37 \pm 1.92 \mathrm{a}$ & $6.40 \pm 1.67 \mathrm{ab}$ \\
Sweetness & $5.93 \pm 2.15^{\mathrm{a}}$ & $6.45 \pm 1.93 \mathrm{a}$ & $6.48 \pm 1.72^{\mathrm{a}}$ \\
Acidity & $5.98 \pm 2.27^{\mathrm{a}}$ & $6.42 \pm 1.79 \mathrm{a}$ & $6.60 \pm 1.72^{\mathrm{a}}$ \\
Body & $5.97 \pm 1.93 \mathrm{~b}$ & $6.62 \pm 1.53 \mathrm{ab}$ & $6.93 \pm 1.38^{\mathrm{a}}$ \\
Overall acceptance & $5.98 \pm 1.97 \mathrm{~b}$ & $6.77 \pm 1.50 \mathrm{a}$ & $6.87 \pm 1.50^{\mathrm{a}}$ \\
\hline
\end{tabular}

Means with different letters in the formulation's columns differ according to the Friedman test (p<0.05). ${ }^{1} \mathrm{~F} 1: 30 \%$ cupuassu pulp / 70\% green tea; F2: 50\% cupuassu pulp / 50\% green tea; F3: 70\% cupuassu pulp/ 30\% green tea. 
For the flavor, the smaller acceptance of F1 can be associated with bitter and astringent taste. According to reference [36], infusions obtained from the milled leaves have a more bitter and astringent taste, being an indicator of the presence of more phytochemicals. The astringency can be attributed to gallated flavonols and the aflavins, in particular to mono-and di-gallate, and also to catechins, caffeine and some amino acids (such as arginine and alanine) that contribute to the bitterness of green tea infusions [8].

The similarity in the sweetness acceptance obtained herein confirmed the values of total sugars (Table 1 ), that was standardized in the formulations. For the acidity, the sensory results can be associated with $\mathrm{pH}$ (Table 1) that also not changed.

According to reference [37], the consumer preference responses are usually heterogeneous, and the means may not be representative of any individual opinion. Thus, the awareness of interindividual differences in preference behavior gave rise to increasing popularity of consumer segmentation. In this case, the Principal component analysis (PCA) is applied. In the present study, the PCA was used in the overall acceptance data. The PCA1 (F1) explained $62.26 \%$ and the PCA2 (F2) $25.49 \%$ (Figure 1). Thus, the sum of the two PCA is $87.75 \%$, being high than $70 \%$. The percentage is sufficient to represent the dispersion of the formulations, explaining most of the variation of the data. Therefore, there is a two-dimensional presentation of easy interpretation [38]. In Figure 1, each point represents the correlations between the consumer acceptance data with the two principal components. In the graph, it is possible to observe the presence of two distinct groups, being 1 formed by F1, in quadrant 4 and the other by $\mathrm{F} 2$ and $\mathrm{F} 3$ in quadrant 1 .

The reference [39] reported that in this type of graphical representation consumers are near the region of the samples most accepted by them. Therefore, evaluating the quadrant 1 can be observed that nectars of F2 were more accepted.

Thus, F2 and F3 were the most accepted, with emphasis on F2. Moreover, considering that of these two formulations, F3 had lower antioxidant activity (Table 1), which is an essential nutritional characteristic, and F2 could provide more nutrients from raw materials, F2 was selected for the production of mixed nectar of cupuassu and green tea.

\subsection{Ideal Sweetness in the Mixed Nectar of Cupuassu and Green Tea}

For ideal sweetness, all concentration of soluble solids had good acceptance because the sensory attributes were positively scored, with a rating between "like slightly" and "like very much" (6-8). For the flavor, $15^{\circ}$ Brix had high $(p<0.05)$ acceptance when compared with $11^{\circ}$ Brix. The nectars with $13{ }^{\circ}$ Brix did not differ those of other treatments. The sweetness of $13^{\circ}$ Brix treatment had high acceptance than $11{ }^{\circ}$ Brix. The nectars with $11^{\circ}$ Brix did not alter those other treatments (Table 3). Thus, treatments with high soluble solids were more accepted.

A similar result was reported by reference [40] in papaya nectars. These authors observed that the higher concentration of the sucrose content increased the acceptance.

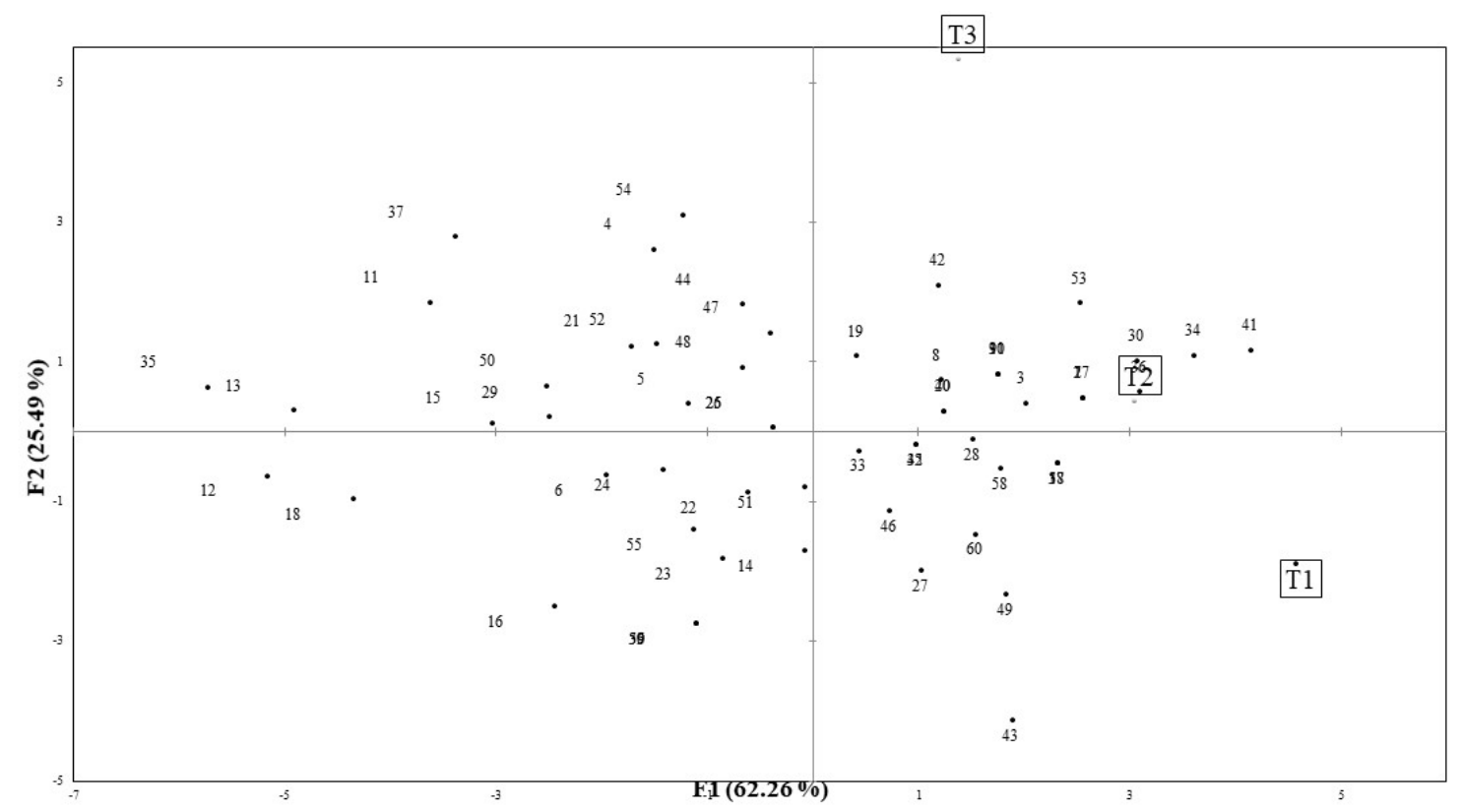

Figure 1. Representation of the formulations for the overall acceptance in the first and second Principal component analysis (PCA) of mixed nectar of cupuassu and green tea with different ratio of vegetables in the mixed base

Table 3. Mean values and standard deviation of the sensory attributes flavor and sweetness of mixed nectar of cupuassu and green tea with different soluble solids contents

\begin{tabular}{|c|c|c|c|}
\hline Attributes & $11^{\circ}$ Brix & $13^{\circ}$ Brix & $15^{\circ}$ Brix \\
\hline Flavor & $6.85 \pm 1.84 b$ & $7.53 \pm 1.36 \mathrm{ab}$ & $7.82 \pm 1.36 a$ \\
\hline Sweetness & $6.83 \pm 1.87 b$ & $7.55 \pm 1.45^{\mathrm{a}}$ & $7.52 \pm 1.49 \mathrm{ab}$ \\
\hline
\end{tabular}

Means with different letters in the formulation's columns differ according to the Friedman test $(\mathrm{p}<0.05)$. 


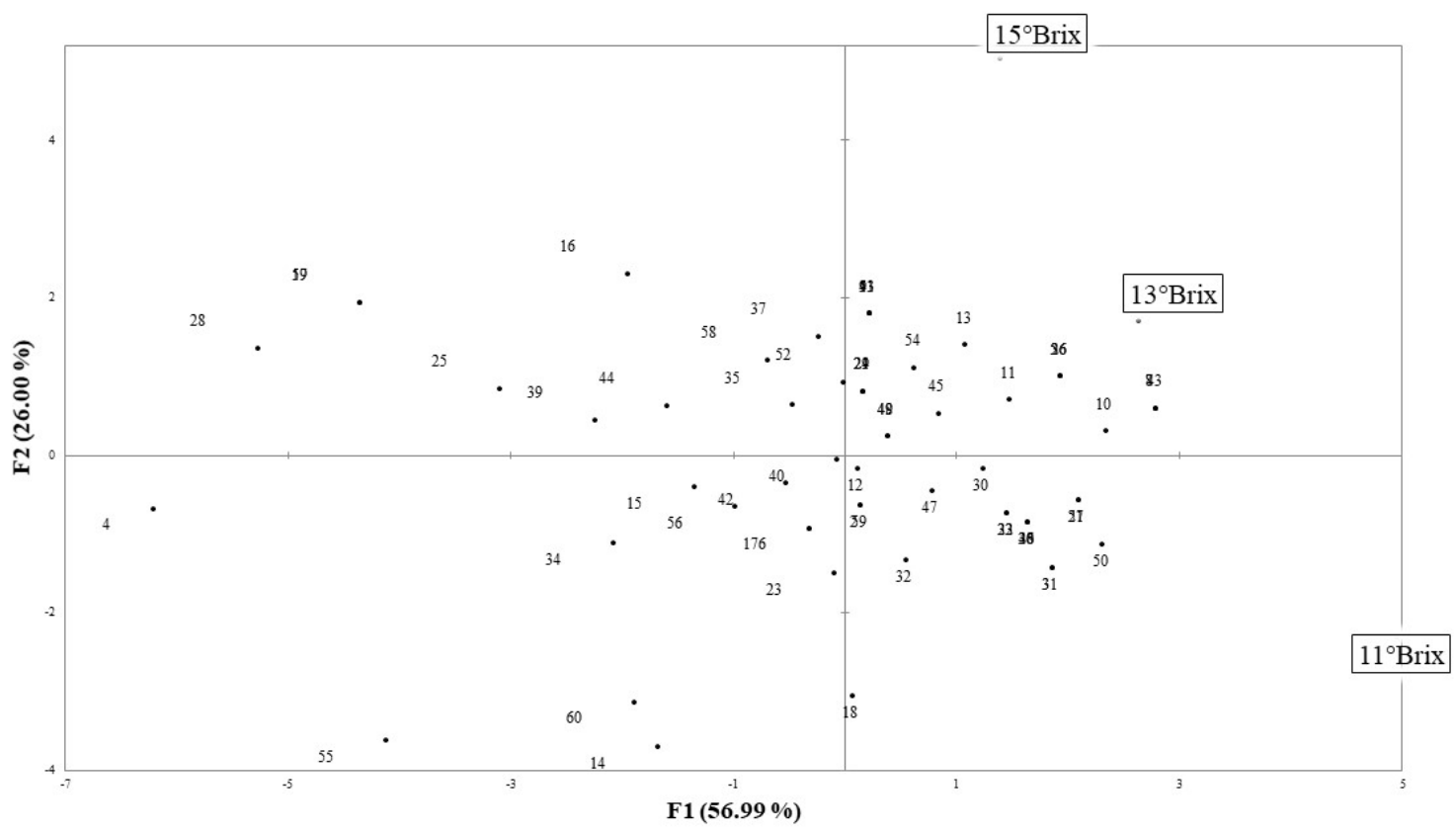

Figure 2. Representation of the formulations for the overall acceptance in the first and second Principal component analysis (PCA) of mixed nectar of cupuassu and green tea with different soluble solids contents

For the data of overall acceptance, the PCA generated explained $82.99 \%$ of the total variation between the treatments, being sufficient to represent the dispersion (Figure 2). In the graph, it is possible to observe the presence of two distinct groups, being 1 formed by $11^{\circ}$ Brix, in quadrant 4 and the other by 13 and $15{ }^{\circ}$ Brix in quadrant 1 . The nectars with $13^{\circ}$ Brix showed more accepted because the consumers were near to this treatment in the graph. Thus, the concentration of $13^{\circ}$ Brix was chosen in this study.

The reference [41] reported lower concentration (9.4 ${ }^{\circ}$ Brix) as the ideal in passion fruit juice. However, as indicated by the reference [42], the sucrose amount in the fruit juices cannot be generalized. The ideal sweetness can vary according to the fruit in the manufacturing process. Thus, the ideal sweetness should be determined for each sample. Therefore, it is essential to evaluate the sweetness of the product.

\subsection{Storage of the Mixed Nectar of Cupuassu and Green Tea}

The microbiological analysis of the mixed nectars showed the absence of total coliforms $(<3 \mathrm{MPN} / \mathrm{mL})$.
Moreover, the lack of mold and yeast counts ( $<10 \mathrm{CFU} / \mathrm{mL}$ ) was also observed. Thus, product safety and suitability for sensory tests were guaranteed [43].

The $\mathrm{pH}$ values were unaffected $(\mathrm{p}>0.05)$ over the storage period. However, it was high $(\mathrm{p}<0.05)$ in the treatments containing preservatives (T2 and T4). Thus, preservatives use increase the $\mathrm{pH}$ of the beverage (Table 4).

For storage time, the reference [44], evaluating the $\mathrm{pH}$ of the mixed beverage produced with green tea and apple also did not observe the storage influence. Regarding the use of preservatives, the reference [45] also reported high $\mathrm{pH}$ when used the potassium sorbate and sodium metabisulphite on the coconut water stability. These authors observed that the samples that did not receive preservative presented less stability. In the present study, the absence of preservatives not affected the stability of mixed nectar. This result is positive because there is no need to add additives.

The titratable acidity did not change concerning the preservative addition nor the storage $(\mathrm{p}>0.05)$ (Table 4$)$. Therefore, the changes observed on the $\mathrm{pH}$ did not influence this parameter.

Table 4. Mean values and standard deviation of the physicochemical analysis of mixed nectar of cupuassu and green tea stored for 180 days at room temperature $\left(25^{\circ} \mathrm{C}\right)$ with and without the use of preservatives.

\begin{tabular}{|c|c|c|c|c|}
\hline Parameters & T1 & $\mathrm{T} 2$ & T3 & T4 \\
\hline $\mathrm{pH}$ & $3.33 \pm 0.03 b$ & $3.52 \pm 0.02 \mathrm{a}$ & $3.29 \pm 0.01 b$ & $3.50 \pm 0.02 \mathrm{a}$ \\
\hline Titratable acidity $^{2}$ & $0.35 \pm 0.01 \mathrm{a}$ & $0.33 \pm 0.01 \mathrm{a}$ & $0.34 \pm 0.00 \mathrm{a}$ & $0.33 \pm 0.01 \mathrm{a}$ \\
\hline Reducing sugars $^{3}$ & $1.83 \pm 0.88 \mathrm{~b}$ & $1.25 \pm 0.45 b$ & $2.88 \pm 0.50 \mathrm{a}$ & $2.37 \pm 0.73 a$ \\
\hline Total sugars $^{3}$ & $8.35 \pm 0.84 b$ & $9.58 \pm 0.66 \mathrm{ab}$ & $9.10 \pm 0.86 \mathrm{ab}$ & $9.82 \pm 0.64 \mathrm{a}$ \\
\hline Phenolic compounds ${ }^{4}$ & $90.15 \pm 2.92 \mathrm{a}$ & $98.51 \pm 4.74 \mathrm{a}$ & $44.95 \pm 1.45 b$ & $44.40 \pm 0.61 \mathrm{~b}$ \\
\hline $\mathrm{AA}(\mathrm{ABTS})^{5}$ & $0.46 \pm 0.04^{\mathrm{a}}$ & $0.44 \pm 0.08 \mathrm{a}$ & $0.42 \pm 0.01 \mathrm{a}$ & $0.43 \pm 0.02 \mathrm{a}$ \\
\hline $\mathrm{AA}(\mathrm{DPPH})^{5}$ & $0.14 \pm 0.02^{\mathrm{a}}$ & $0.13 \pm 0.01 \mathrm{a}$ & $0.07 \pm 0.01 b$ & $0.08 \pm 0.02 b$ \\
\hline Color component L* & $31.51 \pm 3.95 \mathrm{a}$ & $30.68 \pm 1.04 a$ & $33.75 \pm 4.93 a$ & $32.35 \pm 6.84 a$ \\
\hline Color component $\mathrm{a}^{*}$ & $-0.95 \pm 0.17 \mathrm{bc}$ & $-1.18 \pm 0.11 \mathrm{c}$ & $0.37 \pm 0.47 \mathrm{a}$ & $-0.09 \pm 0.82 \mathrm{ab}$ \\
\hline Color component b* & $2.37 \pm 0.68^{\mathrm{a}}$ & $2.92 \pm 0.27 \mathrm{a}$ & $2.17 \pm 0.87 \mathrm{a}$ & $1.78 \pm 1.19 \mathrm{a}$ \\
\hline
\end{tabular}

Means with different letters in the formulation's columns differ according to the Tukey test $(\mathrm{p}<0.05)$.

${ }^{1} \mathrm{~T} 1$ : day 0 without preservatives; T2: day 0 with preservatives T3: day 180 without preservatives; T4: day 180 with preservatives. ${ }^{2} \mathrm{~g} / 100$ $\mathrm{mL}$ of citric acid; ${ }^{3} \mathrm{~g} / 100 \mathrm{~mL}$ of glucose; ${ }^{4} \mathrm{mg}$ of gallic acid/ $100 \mathrm{~mL} ; 5 \mathrm{AA}=$ antioxidant activity $(\mu \mathrm{M}$ Trolox/ mL). 
The stability of the acidity obtained in the present study indicates that there was no significant degradation of the acids present in the nectars. The reference [46] observed acidity reduction during the storage of tropical acerola juice and attributed this reduction to oxidation of organic acids.

For reducing sugars, T3 and T4 had higher $(\mathrm{p}<0.05)$ values (Table 4). Thus, it was observed the effect of storage to increase these compounds. The reference [47] also reported increased in reducing sugars of kinnow juice for 30 days. These authors said which may be resultant of the gradual conversion of a non-reducing sugar, non-sugar carbohydrates, and acids into reducing sugar.

The total sugars of the treatment containing preservatives and stored for 180 days were higher $(p<0.05)$ than that of treatment without preservatives and with 0 days of storage (Table 4). The reference [48] also reported an increase in the total sugars of mulberry juice containing preservatives after 180 days of storage.

The phenolic compounds of $\mathrm{T} 3$ and $\mathrm{T} 4$ were the lowest $(p<0.05)$ (Table 4). Thus, it was observed the effect of storage in the reduction of these bioactive compounds. The reference [29] reported losses of $53.04 \%$ of the phenolic content in the mixed juices containing Hibiscus sabdariffa L., papaya, guava and mango with 180 days. According to reference [49], the decrease in phenolic content and antioxidant activity during storage may be due to the presence of dissolved oxygen in samples, which resulted in the oxidation of compounds. Herein, the reduction was similar to these authors (50.14\% - 54.92\%).

The antioxidant activity measured for ABTS there did not change between treatments, similar to the results for the chose the ratio of cupuassu and green tea in the mixed nectar. DPPH method had similar effects of phenolics compounds, with reduction $(\mathrm{p}<0.05)$ during storage (Table 4).

The reference [50] also reported a decrease in the quince nectar during storage. According to these authors, the reduction in antioxidant activity during storage may be attributed to the degradation of bioactive compounds such as phenolic compounds. Thus, the reduction of antioxidant activity of the present study is related to the decrease of phenolic compounds.

For the color components, $\mathrm{L}^{*}$ and $\mathrm{b}^{*}$ did not change among the treatments. The color component $\mathrm{a}^{*}$, T1 had high $(\mathrm{p}<0.05)$ values than T3 and T2 had high $(\mathrm{p}<0.05)$ values than T4 (Table 4). Thus, this result indicates that the redness increased with the storage, independent of the use of preservatives.

The reference [51] also reported increased of redness during storage of the orange juice pasteurized. According to these authors, the increased can be a consequence of the non-enzymatic browning reactions, such as the Maillard reaction.

The sensory attributes flavor, sweetness, acidity, and body did not change ( $>0.05$ ) between the treatments. The acceptance attributes color and appearance were lower in T3 and T4. The approval reduced with the storage (Table 5).

For the color and appearance, the reference [52] also reported reduced in the color acceptance in the low-fat cupuassu and açaí nectar after 180 days of storage. These authors associated low approval with the changes in the instrumental color. In the present study, the reduced in the approval also can be related to increasing the redness, as a result of the non-enzymatic browning reactions.

For the aroma, T1 had high acceptance when compared to T3. Therefore, the samples without preservatives had changes during storage. T2 did not differ from T4, indicating that the preservatives were efficient in maintaining the aroma during storage (Table 5). Despite the reduction, it was kept good acceptance because the attribute was positively scored, rating between "like slightly" and "like moderately" (6-7). This reduction is the consequence of volatile compounds losses that occur with storage. The reference [53] reported the decline in the volatile compounds of bayberry juice, that was associated with the increase of alcohol flavors and a decrease of esters flavors.

For the data of overall acceptance, the CPA explained $68.86 \%$ of the variation between the treatments (Figure 3 ). In the graph, it was observed two distinct groups, being 1 formed by $\mathrm{T} 1, \mathrm{~T} 2$, and $\mathrm{T} 4$, in quadrant 4 and the other by T3 in quadrant 1 . Therefore, the sample without preservatives stored for 180 days (T3) differed of the other treatments.

Thus, the samples without preservatives had some changes in the sensory characteristics during storage (T3). Despite the reduction, these characteristics were maintained in the acceptance region of the hedonic scale.

Table 5. Mean values and standard deviation of the sensory attributes color, appearance, aroma, flavor, sweetness, acidity, and body of mixed nectar of cupuassu and green tea stored for 180 days at room temperature $\left(25^{\circ} \mathrm{C}\right)$ with and without the use of preservatives.

\begin{tabular}{|c|c|c|c|c|}
\hline Attributes & $\mathrm{T} 1$ & $\mathrm{~T} 2$ & Т3 & $\mathrm{T} 4$ \\
\hline Color & $7.53 \pm 1.33 a$ & $7.75 \pm 1.31 \mathrm{a}$ & $5.60 \pm 1.98 b$ & $5.80 \pm 1.96 \mathrm{~b}$ \\
\hline Appearance & $7.50 \pm 1.28 a$ & $7.73 \pm 1.19 a$ & $5.73 \pm 1.87 \mathrm{~b}$ & $5.90 \pm 1.91 b$ \\
\hline Aroma & $7.02 \pm 1.70 \mathrm{a}$ & $6.80 \pm 1.63 a b$ & $6.27 \pm 1.83 b$ & $6.35 \pm 1.79 b$ \\
\hline Flavor & $6.85 \pm 1.76 a$ & $6.55 \pm 1.80 a$ & $6.25 \pm 1.91 a$ & $6.12 \pm 2.01 \mathrm{a}$ \\
\hline Sweetness & $6.88 \pm 1.67 a$ & $6.58 \pm 1.85 a$ & $6.43 \pm 1.95 a$ & $6.65 \pm 1.80 \mathrm{a}$ \\
\hline Acidity & $6.67 \pm 1.95 a$ & $6.58 \pm 1.94 a$ & $6.43 \pm 1.85 a$ & $6.47 \pm 1.85 a$ \\
\hline Body & $7.02 \pm 1.33 a$ & $6.90 \pm 1.30 \mathrm{a}$ & $6.45 \pm 1.56 a$ & $6.65 \pm 1.72 \mathrm{a}$ \\
\hline
\end{tabular}

Means with different letters in the formulation's columns differ according to the Friedman test $(\mathrm{p}<0.05)$.

${ }^{1} \mathrm{~T} 1$ : day 0 without preservatives; T2: day 0 with preservatives T3: day 180 without preservatives; T4: day 180 with preservatives. 


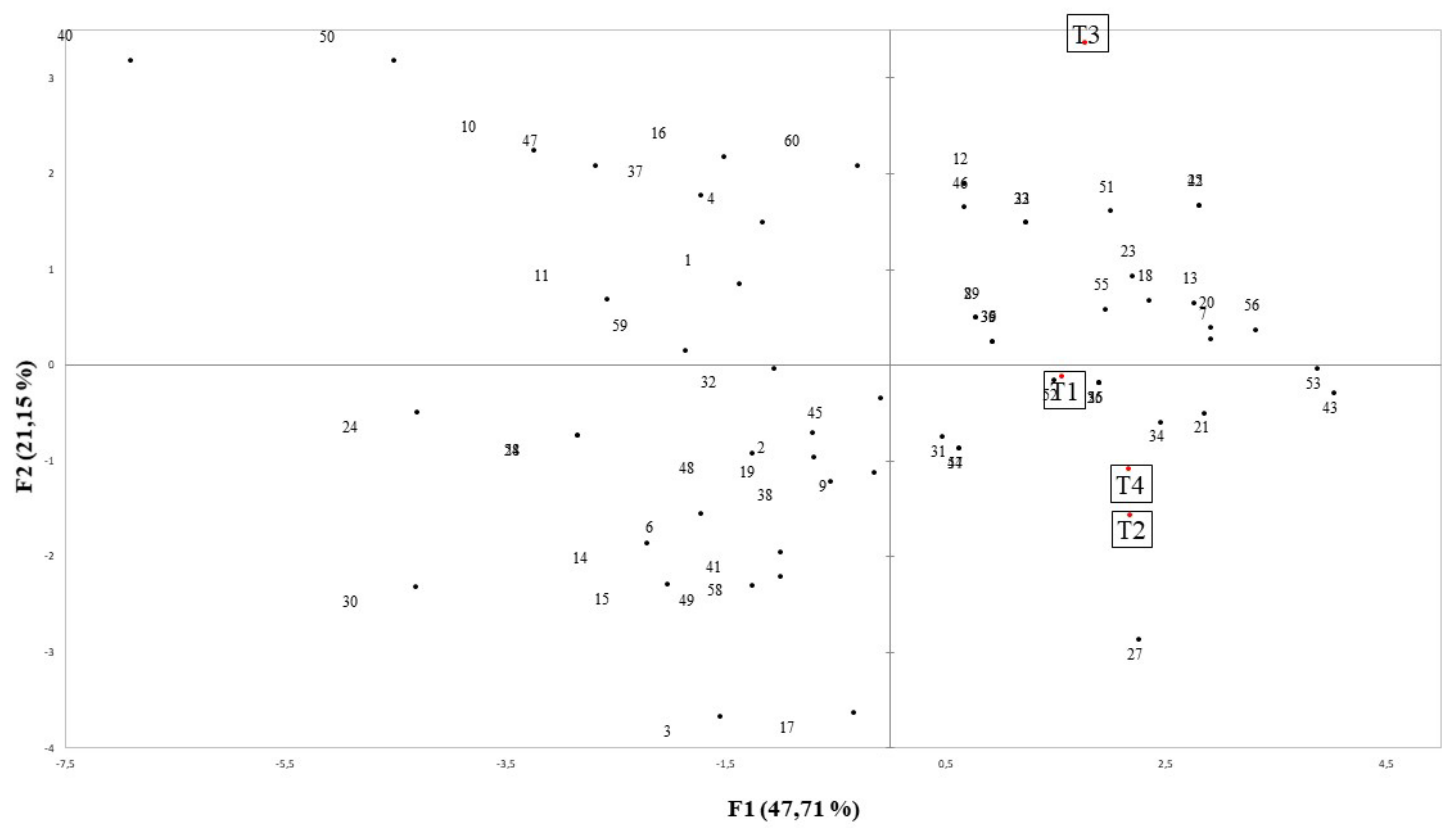

Figure 3. Representation of the formulations for the overall acceptance in the first and second Principal component analysis (PCA) of mixed nectar of cupuassu and green tea stored for 180 days at room temperature $\left(25^{\circ} \mathrm{C}\right)$ with and without the use of preservatives

\section{Conclusion}

The mixed nectars of cupuassu and green tea obtained satisfactory results for the nutritional value and sensory acceptance. The formulation selected for the blend nectar production was: $50 \%$ cupuassu pulp and $50 \%$ green tea at the mixed base and total soluble solids content of $13^{\circ}$ Brix.

For the stability, the nectars obtained good sensory acceptance, since did not have changes in taste, sweetness, acidity, and body by the addition of preservatives and storage. However, there was a reduction in compounds phenolics, antioxidant activity, and color acceptance during storage, that was not altered by the use of preservatives sodium metabisulfite and potassium sorbate.

Therefore, it can be concluded that the production of mixed nectar of cupuassu and green tea nectar is a promising product for the market of beverage. The production of nectar without preservatives sodium metabisulfite and potassium sorbate is possible.

\section{Conflicts of Interest}

All authors declare no competing interests.

\section{Acknowledgments}

Authors thank the National Institute of Tropical Fruits, The National Council for Scientific and Technological Development, Technological Development of Maranhão for the financial support and University Federal of Maranhão for the scholarships.

\section{References}

[1] Demir, F., Kipcak, A.S., Ozdemir, O.D., Derun, E. M., and Piskin, S., "Determination and comparison of come elements in different types of orange juices and investigation of health effects", Int $J$ Nutr Food Eng. 9, 545-549, 2015.

[2] Barbalho, S.M., Otoboni, A.M., Marinelli, P., Bezerra, C.N.O., and Meneghini, A., "Brazilian peach (Prunus Persica) and passion fruit (Passiflora Edulis) nectars: Good source of vitamin C and anthocyanins?”, J Food Res, 5, 50-57, 2016.

[3] Akusu, O.M., Kiin-kabari, D.B., and Ebere, C.O., "Quality Characteristics of Orange/ Pineapple Fruit Juice Blends", Am J Food Sci Technol, 4, 43-47, 2016.

[4] Bamidele, O.P., and Fasogbon, M.B., "Chemical and antioxidant properties of snake tomato (Trichosanthes cucumerina) juice and pineapple (Ananas comosus) juice blends and their changes during storage", Food Chem, 220, 184-189, 2017.

[5] Ogundele, O.M.A., Awolu, O.O., Badejo, A.A., Nwachukwu, I.D., and Fagbemi, T.N., "Development of functional beverages from blends of Hibiscus sabdariffa extract and selected fruit juices for optimal antioxidant properties", Food Sci Nutr, 4, 679-685, 2016.

[6] Saklar, S., Ertas, E., Ozdemir, I.S., and Karadeniz, B., "Effects of different brewing conditions on catechin content and sensory acceptance in Turkish green tea infusions", J Food Sci Technol, 52, 6639-6646, 2015.

[7] Lang'at, N.K., Thoruwa, T., Abraham, J., and Wanyoko, J., "Performance of an iImproved fluidized system for processing green tea", Int J Mech Aerospace Ind Mech Manuf Eng, 10, 1121-1126, 2016.

[8] Chaturvedula, V.S.P., and Prakash, I., "The aroma, taste, color and bioactive constituents of tea", J Med Plants Res, 5, 2110-2124, 2011.

[9] Senanayake, S.P.J.N., "Green tea extract: chemistry, antioxidant properties and food applications - A review", J Funct Foods, 5, 1529-1541, 2013.

[10] Alvarenga, T.N.V., Abreu, V.K.G., Pereira, A.L.F., and Lemos T.O., "Desarrollo y evaluación sensorial de néctar mixto de piña y té verde", RECyT, 18, 26-31, 2016.

[11] Costa, M.P., Monteiro, M.L.G., Frasao, B.S., Silva, V.L.M. Rodrigues, B.L., Chiappini, C.C.J., and Conte-junior, C.A., "Consumer perception, health information, and instrumental parameters of cupuassu (Theobroma grandiflorum) goat milk yogurts", J Dairy Sci, 100, 1-12, 2017.

[12] Pereira, A.L.F., Feitosa, W.S.C., Abreu, V.K.G., Lemos, T.O., Gomes, W.F., Narain, N., and Rodrigues, S., "Impact of fermentation conditions on the quality and sensory properties of a probiotic cupuassu (Theobroma grandiflorum) beverage", Food Res Int, 100, 603-611, 2017.

[13] Pereira, A. L.F., Abreu, V.K.G., and Rodrigues, S., Cupuassu - Theobroma grandiflorum. Exotic fruits. Elsevier Inc, 2018, 159-162. 
[14] Pugliese, A.G., Tomas-barberan, F.A., Truchado, P., Genovese M.I., and Prestes, L. 2013., "Flavonoids, proanthocyanidins, vitamin C, and antioxidant activity of Theobroma grandiflorum (cupuassu) pulp and seeds", J Agric Food Chem, 61, 2720-2728, 2013.

[15] Pinent, M., Castell-Auví A., Genovese, M.I., Serrano, J., Casanova, A., Blay, M., and Ardévol, A., "Antioxidant effects of proanthocyanidin-rich natural extracts from grape seed and cupuassu on gastrointestinal mucosa", J Sci Food Agric, 96, 178-182, 2016.

[16] Vriesmann, L.C., and Petkowicz, C.L.O., "Polysaccharides from the pulp of cupuassu (Theobroma grandiflorum): structural characterization of a pectic fraction", Carbohydr Polym, 77, 72-79, 2009.

[17] Wibowo, S., Grauwet, T., Gedefa, G.B., Hendrickx, M., and Loey, A.V., "Quality changes of pasteurised mango juice during storage. Part II: Kinetic modelling of the shelf-life markers", Food Res Inter, 410-423, 2015

[18] Qiu, S., and Wang, J., "The prediction of food additives in the fruit juice based on electronic nose with chemometrics", Food Chem, 230, 208-214, 2017.

[19] Klaric, D.A., Klaric, I., Mornar, A., and Nigovic, B., "Evaluation of volatile compound and food additive contents in blackberry wine" Food Control, 50, 714-721, 2015.

[20] AOAC, Official Methods of Analysis of the Association of Official Analytical Chemists, 2012.

[21] Miller, G. L., "Use of dinitrosalicylic acid reagent for determination of reducing sugar", Anal Chem, 31, 426-428, 1959.

[22] Singleton, V.L., and Rossi, J.A., "Colorimetry of total phenolics with phosphomolybdic phosphotungstic acid reagents", Am J Enol Vit, 16, 144-158, 1965.

[23] Re, R., Pellegrini, N., Proteggente, A., Pannala, A., Yang, M., and Rice-Evans, C., "Antioxidant activity applying an improved ABTS radical cation decolorization assay" Free Radic Biol Med, 26 , 1231-1237, 1999.

[24] Brand-Williams, Cuvelier, M. E., and Berset, C., "Use of a free radical method to evaluate antioxidant activity" Food Sci Technol, 28, 25-30, 1995.

[25] Vendrúsculo, A.T., and Quadri, M.G.N., "Efeito dos tratamentos enzimático, térmico e mecânico na estabilidade do suco de carambola (Averrhoa carambola L.)", Braz J Food Technol, 11, 28-34, 2008.

[26] Silva, V.M., Carla, A., Sato, K., Barbosa, G., and Dacanal, G. "Original article The effect of homogenisation on the stability of pineapple pulp", Int J Food Sci Technol, 45, 2127-2133, 2010.

[27] American Public Health Association, Compendium of methods for the microbiological examination of foods, Washington D C, 2001, $676 \mathrm{p}$.

[28] Stone, H., and Sidel, J.L., Sensory evaluation practices, 3rd ed., Boston: Academic Press, 2004

[29] Mgaya-Kilima, B., Remberg, S.F., Chove, B.E., and Wicklund, T., "Influence of storage temperature and time on the physicochemical and bioactive properties of roselle-fruit juice blends in plastic bottle", Food Sci Nutr, 2, 181-191, 2014.

[30] Dafny-Yalin, M., Glazer, I., Bar-Ilan, I., Kerem, Z., Holland, D., and Amir, R., "Color, sugars and organic acids composition in ari juices and peel homogenates prepared from different pomegranate accessions", J Agric Food Chem, 58, 4342-4352, 2010.

[31] Dai, Q., He, Y., Ho, C-T., Wang, J., Wang, S., Yang, Y., Gao, L., and Xia, T., "Effect of interaction of epigallocatechin gallate and flavonols on color alteration of simulative green tea infusion after thermal treatment", J Food Sci Technol, 9, 2919-2928, 2017.

[32] Almeida, M.M.B, Sousa, P.H.M., Arriaga, A.M.C., Prado, G.M., Magalhães, C.E.C., Maia, G.A., and Lemos, T.L.G., "Bioactive compounds and antioxidant activity of fresh exotic fruits from northeastern Brazil", Food Res Int J, 44, 2155-2159, 2011.

[33] Veljkovic, J.N., Pavlovic, A.N., Mitic, S., Tosic, S.B., Stojanovic, G.S., Kalicanin, B.M., Sankovic, M.B., Stojkovic, M.B., Mitic, M.N., and Brcanovic, J.M., "Evaluation of individual phenolic compounds and antioxidant properties of black, green, herbal and fruit tea infusions consumed in Serbia: spectrophotometrical and electrochemical approaches", J Food Nutr Res, 52, 12-24, 2013.
[34] Rojas, M.L., Leite, T,S,, Cristianini, M., Alvim, I.D.; and Augusto, P.E.D., "Peach juice processed by the ultrasound technology: Changes in its microstructure improve its physical properties and stability", Food Res Int, 82, 22-33, 2016.

[35] Higa, F., Koppel, K., and Chambers, E., "Effect of additional information on consumer acceptance: an example with pomegranate juice and green tea blends", Beverages, 3, 1-13, 2017.

[36] Castiglioni, S., Damiani, E., Astolfi, P., and Carloni, P., "Influence of steeping conditions (time, temperature, and particle size) on antioxidant properties and sensory attributes of some white and green teas", Int J Food Sci Nutr, 66, 491-497, 2015.

[37] Alves, L.R., Battochio, J.R., Cardoso, J.M.P., Melo, L.L.M.N., Silva, V.S., Siqueira, A.C.P., and Bolini, H.M.A., "Time-intensity profile and internal preference mapping of strawberry jam", $J$ sens stud, 23, 125-135, 2008.

[38] Viana, E.S., Jesus, J.L., Reis ,R.C., Fonseca, M.M., and Sacramento, C.K., "Caracterização físico-química e sensorial de geleia de mamão com araçá-boi", Rev Bras Frutic, 34, 1154-1164, 2012.

[39] Barbosa, A.F., Lopes, F.J., Silva, V.R.O., Silva, M.H.L., Minim, V.P.R., and Silva, R.C.S.N., "Sensory acceptance of peachflavored yogurt supplemented with different aroma and pulp concentrations assessed by the preference mapping technique", Rev Inst Latic Candido Tostes, 68, 52-58, 2013.

[40] Braga, H.F., and Conti-Silva, A.C., "Determination of ideal sweetness in nectar of papaya with sugar", Ciênc Rural, 44, 723-727, 2014.

[41] Rocha, I.F.O., and Bolini, H.M.A., "Different sweeteners in passion fruit juice: ideal and equivalent sweerness", LWT, 62, 861-867, 2015.

[42] Cadena, R.S., and Bolini, H.M.A., "Ideal and relative sweetness of high intensity sweeteners in mango nectar", Int J Food Sci Technol, 47, 991-996, 2012.

[43] Brasil, Resolução - RDC $N^{\circ}$ 12, de 02 de janeiro de 2001, ANVISA - Agência Nacional de Vigilância Sanitária, 2001.

[44] Rubio-Perez, J.M., Vidal-Guevara, M.L., Zafrilla, P., and Morillas-Rui, z J.M., "A new antioxidant beverage produced with green tea and apple", Int J Food Sci Nutr, 65, 552-557, 2014.

[45] Pereira, E.P.R., Faria, J.A.F., and Pinto, U.M., "Optimizing the use of potassium sorbate and sodium metabisulphite for the chemical and microbial stability of carbonated coconut water", Braz J Food Technol, 16, 125-135, 2013.

[46] Freitas, C.A., Maia, G.A., Costa, J.M.C., Figueiredo, R.W., Rodrigues, M.C.P., and Sousa, P.H.M.S., "Estabilidade do suco tropical de acerola (Malpighia emarginata d.c.) adoçado envasado pelos processos hot-fill e asséptico", Food Sci Technol, 26, 544-549, 2006.

[47] Dhaka, A., Sharma, M., and Singh, S.K., "Use of additives to reduce browning, microbial load and quality loss of Kinnow juice under ambient storage", Indian J Sci Technol, 9, 1-11, 2016.

[48] Yadav, P., Garg, N., and Kumar, S., "Improved shelf stability of mulberry juice by combination of preservatives", Indian J Nat Prod Resour, 5, 62-66, 2014.

[49] Nematollahi, A., Sohrabvandi, S., Mortazavian, AM., and Jazaeri, S., "Viability of probiotic bacteria and some chemical and sensory characteristics in cornelian cherry juice during cold storage", EJBT, 21, 49-53, 2016.

[50] Yilmaz, E., and Karadeniz, F., "Effect of storage on the bioactive compounds and antioxidant activity of quince nectar", Int J Food Sci Technol, 49, 718-725, 2014.

[51] Cortés, C., Esteve, M.J., and Frígola, A., "Color of orange juice treated by high intensity pulsed electric fields during refrigerated storage and comparison with pasteurized juice", Food Control, 19, 151-158, 2008.

[52] Fernandes, E.T.M.B., Maciel, V.T., Souza, M.L., Furtado, C.D.M., Oliveira, L.H., and Cunha, C.R., "Physicochemical composition , color and sensory acceptance of low-fat cupuaçu and açaí nectar: characterization and changes during storage", Food Sci Techonol, 36, 413-420, 2016.

[53] Xu, Y.X., Zhang, M., Fang, Z.X., Sun, J.C., and Wang, Y.Q., "How to improve bayberry (Myrica rubra Sieb. et Zucc.) juice flavour quality: Effect of juice processing and storage on volatile compounds", Food Chem, 151, 40-46, 2014. 